\title{
Homework Instructions and Compliance Assessing in the Therapeutic Process: An Analysis of Therapists' Verbal Behavior*
}

\section{Instrucciones sobre las tareas terapéuticas y evaluación del cumplimiento durante el proceso terapéutico: análisis de la conducta verbal del terapeuta}

Received: 11 April 2019 | Accepted: 08 June 2020

\author{
Carlos Marchena Giráldez \\ Universidad Francisco de Vitoria, España \\ ORCID: https://orcid.org/0000-0003-0178-4276 \\ María Xesús Froxán Parga \\ Universidad Autónoma de Madrid, España \\ ORCID: https://orcid.org/0000-0002-6175-4637 \\ Ana Calero Elvira \\ Universidad Autónoma de Madrid, España \\ ORCID: https://orcid.org/0000-0002-1795-3022
}

a Correspondence author. E-mail: carlosalberto.marchena@ufv.es

How to cite: Marchena Giráldez, C., Froxán Parga, M. X., \& Calero Elvira, A. (2020). Homework instructions and compliance assessing in the therapeutic process: An analysis of therapists' verbal behavior. Universitas Psychologica, 19, 1-13. https://do i.org/10.11144/Javeriana.upsy19.hica

\begin{abstract}
Instructions are a common resource used by behavioral therapists to assign therapeutic homework. However, understanding how clients learn with instructions is better known in laboratory research than in clinical research. The present study aims to explore changes in the way of instructing and reviewing the client's compliance throughout the therapeutic process. We analyzed the therapist's verbal behavior during 211 recorded sessions corresponding to 19 cases treated by 11 behavioral therapists (53\% male and $47 \%$ female). The sessions were divided into four stages according to the timing of the intervention and coded by using a previously validated coding system (SYST-INTER-INSTR). Results show that instructions become less specific towards the last stage of the intervention. However, therapists assess task compliance in the same way towards the end of the therapeutic process. The change in specificity suggests that the client's behavior changes from being controlled by instructions to being controlled by natural contingencies. However, to make sure the clinical change remains; therapists assess and reinforce the client's compliance until the end of the intervention. Although clinical implications of the results, some limitations (i.e., not considering the type of task instructed) should be addressed in future studies.
\end{abstract}

Keywords

instructions; homework; verbal behavior; compliance; therapeutic process.

\section{RESUMEN}

Las instrucciones son un recurso utilizado por los terapeutas conductuales para asignar las tareas terapéuticas. No obstante, conocemos más sobre el aprendizaje por instrucciones en el laboratorio que en el campo aplicado. El objetivo del estudio es analizar la forma de instruir y revisa el cumplimiento a lo largo del proceso terapéutico. Se analizó la conducta 
verbal del terapeuta en 211 sesiones de19 casos tratados por 11 terapeutas de orientación conductual (57\% hombres y $47 \%$ mujeres). Se dividieron las sesiones según la fase en la que se encontraba la intervención y se codificaron utilizando un sistema de categorización validado (SIST-INTER-INSTR). Los resultados muestran que las instrucciones se vuelven menos específica hacia el final de la intervención. Sin embargo, la forma de evaluar el cumplimiento permanece estable. Estos resultados sugieren que la conducta del cliente pasa de estar controlada por las instrucciones a estar controlada por las contingencias naturales. Sin embargo, para asegurarse del mantenimiento del cambio clínico, los terapeutas siguen evaluando y reforzando el cumplimiento hasta el final de la intervención. A pesar de las implicaciones clínicas de los resultados, algunas limitaciones (como, por ejemplo, no tener en cuenta el tipo de tarea terapéutica) requieren ser abordadas en futuros estudios.

Palabras clave

instrucciones; tareas; conducta verbal; cumplimiento; proceso terapéutico.

Homework is one of the main tools therapists use to achieve therapeutic goals from a behavioral perspective (Kazantzis et al., 2016). This therapeutic resource entails the use of instructions to encourage the acquisition of new behaviors that will lead to clinical change. However, this behavior acquisition will not be possible if the client does not comply with the assigned homework. As well as providing the instructions, the therapist must ensure that the client is complying by completing the assignment (Coon \& Gallagher-Thompson, 2002); thus, therapeutic interaction and, specifically, the therapist's verbal behavior, is a key element for studying both commitments (Montaño et al. 2013).

However, verbal behavior is not a static element in psychological treatment; it changes throughout the therapeutic process and is also dependent on the therapist's goals (Follette, Naugle, \& Callaghan, 1996; Froján, Montaño, \& Calero, 2010; Rosenfarb, 1992; Ruiz, Froján, \& Calero, 2013; Ruiz, Froján, \& Galván, 2015; Tsai et al., 2009; Vargas et al., 2017). On this basis, it might be expected that how the therapist chooses to give instructions regarding homework and assesses the client's compliance will change over the different stages of the intervention, reflecting how clients incorporate new strategies into their behavioral repertoire. Nevertheless, this process is an issue that is still to be addressed in clinical psychology research.

Homework instructions and compliance assessment have been studied extensively in clinical psychology research, taking the form of guidelines than have traditionally been useful for therapists and, specifically, for new therapists. For example, Shelton and Levy (1981) state that therapists must be specific when they assign therapeutic homework, while others suggest the importance of providing examples or asking for the task to be completed in the clinical setting (Garland \& Scott, 2002; Huppert, Roth, $\&$ Foa, 2006). Others even ask the client for feedback on the task (Cronin, et al., 2015). Regarding the assessment of compliance, the most frequently offered tips for therapists are the importance of asking the client about the homework implementation and any problems encountered, as well as reinforcing compliance (Cronin et al., 2015; Garland \& Scott, 2002; Dattilio, 2002).

However, we find two limitations in clinical psychology research. Firstly, researchers have focused predominantly on analyzing prototypical ways of performing these tasks based on the most appropriate, without taking into account the therapist's therapeutic goals, or the intervention stage. This does not solve the absence of systematicity when therapists instruct and assess the client compliance reported by some researchers (Kazantzis \& Deane, 1999).

Secondly, these studies have been principally built upon the questionnaire and interview method. These are addressed to therapists and clients, who provide information on what therapists and clients report regarding the therapist's performance, rather than an objective examination by an external observer of how a therapist instructs and assesses client's compliance on a session-by-session basis. For example, Conklin, Strunk and Cooper (2018) used a questionnaire to measure therapist behaviors related to homework assignment and compliance assessment to show the relationship 
between a client's engagement with betweensessions homework.

In the experimental field, the use of instructions and the manner of providing instructions have traditionally been a subject of interest in laboratory experiments to analyze their contribution to the learning process (Baron \& Galizio, 1983). The vast majority of these experimental studies have demonstrated that instructions play an important role in the acquisition of a new response, as does the type of instruction used; in particular, the way instructions are given (e.g., the use of accurate or inaccurate instructions) (Kaufman, Baron, \& Kopp, 1966; Lippman \& Meyer, 1967).

Other studies have revealed that instructions are not the only element that influences the acquisition and maintenance of the behavior, but also the interaction with the reinforcement. The researchers involved in these studies concluded that, while the accuracy of instructions is essential at the start of the learning process, the way the contingencies interact with the instructions has a greater impact on maintenance. In other words, these studies suggest that the most appropriate way of giving instructions depends on what stage of the learning process the participant is in, i.e., the stage of the experiment (Ayllon \& Azrin, 1964; Martínez, Ortiz, \& González, 2007; Martínez \& Tamayo, 2005).

To reach their conclusions, behavior analysts manipulate the type of instructions and contingencies throughout several stages or experimental sessions to monitor the changes in the participants' performance (i.e., Kissi et al., 2018). In this regard, we believe that learning processes with instructions that take place in laboratory experiments may be similar to those that occur in clinical treatment, and this may be reflected in changes in the accuracy when a therapist gives instructions for homework and reviews client compliance throughout the treatment stages: moving from a more accurate to a more general model of issuing instructions. However, there is an absence of longitudinal studies addressing this issue due to the lack of interest in the field of clinical research for experimental findings.

Taking into account the unresolved questions and the limitations of previous studies in the clinical field described above, the present study has a twofold objective: firstly, to explore the changes in the verbal behavior of the therapist when giving instructions for homework and assessing the client's compliance by using the observational methodology and, secondly, to use the main conclusions from the experimental field within the framework of the instructions in order to explain the results obtained. Even though the latter is a theoretical aim and refers to the discussion of the results, we consider it of great relevance to establish an initial approach to the applicability of experimental findings in the clinical field. We hypothesize that: (a) therapists' instructions for homework become less accurate by the last stage of the treatment, and (b) therapists also become less accurate when assessing clients' compliance with the instructed homework as the intervention proceeds.

\section{Method}

\section{Participants}

We analyzed 211 recorded clinical sessions, each lasting approximately one hour and encompassing 19 treatment cases. In all cases, clients expressed their consent for the recording and observing the sessions, in adherence to articles 40 and 41 of the Spanish Deontological Code for Psychologists. All clients were adults and were treated by 11 different therapists from a behavioral perspective. Table 1 shows a summary of the sample used in this study. Because the interest of the study lies in a general description of the therapeutic process, from a behavioral perspective, functional analysis is more relevant than diagnostic categories. The type of clinical problem was not considered, but they are detailed for informational purposes. 
Table 1

Characteristics of the sample

\begin{tabular}{|c|c|c|c|c|c|}
\hline Case & $\begin{array}{c}\text { Session number and } \\
\text { duration }^{1}\end{array}$ & $\mathrm{~T}$ & Sex & Age & Problem type \\
\hline 1 & $13(00: 58: 48)$ & 1 & $\mathrm{~F}$ & 29 & Depressed mood \\
\hline 2 & $10(00: 48: 54)$ & 1 & $\mathrm{~F}$ & 32 & Partnership problems \\
\hline 3 & $8(00: 39: 20)$ & 1 & $\mathrm{~F}$ & 36 & Agoraphobia \\
\hline 4 & $10(00: 48: 00)$ & 2 & $\mathrm{M}$ & 42 & Anxiety \\
\hline 5 & $12(00: 59: 21)$ & 2 & $\mathrm{M}$ & 58 & Depressed mood \\
\hline 6 & $13(00: 48: 36)$ & 3 & M & 36 & Anxiety \\
\hline 7 & $8(00: 46: 17)$ & 3 & M & 18 & Panic attacks \\
\hline 8 & $12(01: 01: 55)$ & 4 & M & 48 & Anxiety \\
\hline 9 & $9(00: 56: 44)$ & 5 & $\mathrm{~F}$ & 29 & Anxiety \\
\hline 10 & $12(01: 07: 00)$ & 6 & M & 34 & Hypochondria \\
\hline 11 & $11(01: 04: 31)$ & 7 & $\mathrm{~F}$ & 24 & Family conflicts \\
\hline 12 & $7(00: 48: 47)$ & 2 & $\mathrm{~F}$ & 25 & Eating problems \\
\hline 13 & $8(00: 43: 38)$ & 4 & M & 21 & Arachnophobia \\
\hline 14 & $11(01: 01: 23)$ & 5 & $\mathrm{~F}$ & 34 & Partnership break-up \\
\hline 15 & $8(00: 52: 20)$ & 8 & $\mathrm{~F}$ & 19 & Social skills deficit \\
\hline 16 & $10(01: 09: 29)$ & 9 & M & 22 & Anxiety \\
\hline 17 & $19(00: 53: 00)$ & 10 & M & 22 & Anxiety \\
\hline 18 & $16(01: 01: 25)$ & 10 & M & 22 & Social skills deficit \\
\hline 19 & $14(00: 56: 48)$ & 11 & $\mathrm{~F}$ & 22 & Jealous behavior \\
\hline $\begin{array}{l}\text { Total } \\
(\mathrm{N})\end{array}$ & $211(196 \mathrm{~h} \mathrm{12m} \mathrm{23s)}$ & 11 & $\begin{array}{l}M=53 \% \\
F=47 \%\end{array}$ & $\begin{array}{l}M=30.15 \\
S D=10.6\end{array}$ & \\
\hline
\end{tabular}

$\mathrm{T}=$ Therapist number; $\mathrm{M}=$ Male $\mathrm{F}=$ Female;

${ }^{1}$ Number of the sessions of the case and average time of sessions in each case

Variables and instruments

a. Verbal behavior of the therapist:

We used The Observer XT (C) software (version 12) to observe, code, analyze all the clinical sessions, and compute the intra- and interjudge reliability of registered sessions. The codification of the therapist's verbal behavior was carried out using the therapist's categories described in The Categorization System of the Therapist and the Client's Verbal Behavior During the Instructions Emission and Compliance Review (SYST-INTERINSTR) developed by our research team in order to study the verbal interaction between therapists and clients when therapists assign between-session homework and review the client's compliance. A brief description of the development of this instrument is presented in the procedure section of this study.

Given that therapist verbalizations cannot be understood without the verbal context, we coded instructional blocks, for the session segments in which the therapist assigns betweensessions homework, and compliance review blocks, for the times when the therapist reviews the client's homework compliance during clinical sessions. We considered that the instructional blocks began when the therapist began to assign a specific therapeutic task and finished when the therapist or client changed the speech to another conversation topic or when the therapist began to assign a different task. The compliance review blocks started when the therapist began to assess the compliance of therapeutic tasks (a general or specific task). As for the instructional blocks, the end of compliance review blocks was considered to occur when the therapist or client changed to a different topic of conversation or when the therapist began to assess the compliance of a different task.

Within the two blocks, the therapist's verbal behavior was classified according to the categories included in SYST-INTERINSTR. In addition, we categorized whether the instructional blockscontained components for making the homework assignment more accurate. A description of the categories analyzed within each block, and how the components of instructional blocks are categorized appear in Table 2.

Table 2

Therapists' categories included in SYST-INTERINSTR

\begin{tabular}{|c|c|}
\hline Components of instructional blocks & $\begin{array}{l}\text { Description } \\
\end{array}$ \\
\hline Formal/Informal & $\begin{array}{l}\text { If the therapist instructs/does not instruct homervork } \\
\text { accurately. At least one instruction within the block } \\
\text { must be coded as formal to consider it as a formal } \\
\text { block (see categories within the instructional blocks). }\end{array}$ \\
\hline With/Without a specific situation & $\begin{array}{l}\text { If the therapist specifies/does not specify the } \\
\text { discriminative stimulus on the client when putting the } \\
\text { instructed task into practice. }\end{array}$ \\
\hline With/Without example & $\begin{array}{l}\text { If the therapist gives/does not give examples of how } \\
\text { to perform the task instructed. }\end{array}$ \\
\hline With/Without written instructions & $\begin{array}{l}\text { If the therapist provides written instructions for the } \\
\text { homework assigned to the client. }\end{array}$ \\
\hline With/Without role-playing & $\begin{array}{l}\text { If the therapist practices the instructed task with the } \\
\text { client within the session. }\end{array}$ \\
\hline Categories within the instructional blocks & $\begin{array}{l}\text { Description } \\
\end{array}$ \\
\hline Formal/Informal instruction & $\begin{array}{l}\text { Instruction emitted that accurately specifies/does not } \\
\text { specify the operant response that the client must } \\
\text { implement. }\end{array}$ \\
\hline Viability discriminative & $\begin{array}{l}\text { Verbalization used to assess how feasible the client } \\
\text { considers it will be to carry out the instructed task. }\end{array}$ \\
\hline Difficult discriminative & $\begin{array}{l}\text { Verbalization used to assess the client's doubts or } \\
\text { potential difficulties regarding the instructed task. }\end{array}$ \\
\hline Opinion discriminative & $\begin{array}{l}\text { Verbalization used to assess the client's opinion or } \\
\text { evaluation of the task. }\end{array}$ \\
\hline Performance discriminative & $\begin{array}{l}\text { Verbalization used to assess how the client will carry } \\
\text { out the instructed task. }\end{array}$ \\
\hline Comprehension discriminative & $\begin{array}{l}\text { Verbalization used to assess if the client has } \\
\text { understood the instructed task. }\end{array}$ \\
\hline $\begin{array}{c}\text { Categories within the compliance review } \\
\text { blocks }\end{array}$ & Description \\
\hline Specific compliance discriminative & $\begin{array}{l}\text { Verbalization used to assess client's compliance with } \\
\text { a specific task. }\end{array}$ \\
\hline Non-specific compliance discriminative & $\begin{array}{l}\text { Verbalization used for a general assessment of the } \\
\text { client's task compliance. }\end{array}$ \\
\hline Compliance discriminative of difficulty & $\begin{array}{l}\text { Verbalization used to assess the problems } \\
\text { encountered by the client during the implementation } \\
\text { of the task. }\end{array}$ \\
\hline $\begin{array}{l}\text { Compliance discriminative of } \\
\text { performance }\end{array}$ & $\begin{array}{l}\text { Verbalization used to assess how the client has } \\
\text { carried out the instructed task. }\end{array}$ \\
\hline & $\begin{array}{l}\text { Verbalization showing approval, agreement or } \\
\text { acceptance about the client's compliance of the } \\
\text { instructed task. }\end{array}$ \\
\hline
\end{tabular}

b. Intervention stages: 
We divided the sessions into four different stages relating to the periods of the therapeutic process:

- Assessment: from the first session to the session prior to the one in which a functional analysis explanation is given.

- Explanation: the session in which the therapist explains to the client the functional analysis (the beginning and maintenance hypothesis regarding the problem).

- Treatment: from the first session after the functional analysis explanation session to the session in which the therapist begins to space out the clinical sessions.

- Follow-up: from when therapists move to weekly and fortnightly clinical sessions until the end of the therapy.

\section{Procedure}

The starting point of the study was the instruction categories determined by our team's previous research, but we focused only on those verbalizations used by the therapist when assigning between-session tasks (Froján et al., 2010; Froján \& Ruiz, 2013; Ruiz et al., 2013). First, an expert in behavioral psychological therapy with experience in observational methodology and therapeutic interaction analysis (Observer 1) analyzed different sessions of different cases to propose a preliminary categorization system of therapists' verbal behavior when giving instructions and reviewing the client's compliance. In parallel, a team with expertise in categorization system development reviewed the preliminary categories periodically. In these meetings, categories could be eliminated, modified, or created according to the theoretical and clinical requirements.

After the preliminary categorization system was created, a second observer (Observer 2), also an expert in behavioral psychological therapy and observational methodology, coded the same sessions as Observer 1 to refine the categorization system through the agreement percentage and Cohen's kappa. Disagreements or queries resulting from the comparison were discussed at periodic meetings with the expert team. Conclusions from the meetings were added to the categorization system and taken into account to code the subsequent sessions.

The categorization system refinement stage was completed when the agreement percentage and Cohen's kappa were consistently evaluated between 'good' and 'excellent' (Bakeman, 2000; Landis \& Koch, 1977) in ten consecutive sessions. After the refinement stage, we selected the sample for study and began to observe and code every session. The sessions were divided according to the treatment stages previously described to fulfill the objectives of this study. To guarantee the coding quality, we periodically evaluated the intra- and interjudge reliability by analyzing the agreement percentage and Cohen's kappa. After every complete case coded by Observer 1, two sessions of the same case were coded by Observer 2: a first session is chosen at random (instructional blocks session), and the session after it (compliance review blocks session). In all the comparisons, the agreement percentage and Cohen's kappa retained similar values to those of the categorization system refinement stage. Finally, the data from the coded sessions was exported to SPSS ${ }^{\mathrm{TM}}$ software for analysis.

\section{Data analysis}

Given the non-compliance of ANOVA conditions, we used Friedman's test to compare both hypotheses. Friedman's test is a nonparametric test equivalent to the ANOVA for repeated measures, used to analyze the existence of statistically significant differences in percentages of emission of therapist categories between the intervention stages. When those differences were statistically significant, we also used the Wilcoxon test to analyze the differences between the stages by pairs.

\section{Results}

a) Differences between treatment stages in the way of instructing homework (instructional blocks): 
In order to test the first hypothesis, Table 3 shows the descriptive statistics regarding the components of instructional blocks divided by each stage of the therapeutic process. These results demonstrate a growing trend in the use of formal instructional blocks from the initial stages of the therapeutic process to the Treatment stage, but a decrease in the final stage. In fact, most instructional blocks are formal in all intervention stages (more than 50\%) except in Follow-up, where the most frequent instructional blocks are not formal. The differences between intervention stages were statistically significant $\left(\chi^{2}(3)=11.146 ; p=0.011\right)$. In the comparison by pairs of the therapeutic process stages, we found statistically significant differences between Follow-up and the other three stages: Treatment $(z=-3.582 ; p<0.01)$, Assessment $(z=-2.172$; $p=0.03)$, and Explanation $(z=-2.276 ; p=$ $0.023)$.

Regarding the use of instructional blocks in specific situations, descriptive statistics show some stability throughout all the stages but increased during the Explanation stage. However, no statistically significant differences were found between the intervention stages $\left(\chi^{2}(3)=1.152 ; p=0.765\right)$ as in the case of instructional blocks, for example, although the descriptive statistics showed a decrease in the final stage of the intervention $\left(\chi^{2}(3)=5.227 ; p\right.$ $=0.156)$.

For instructional blocks with written instructions and with role-playing, we found statistically significant differences between intervention stages $\left(\chi^{2}(3)=11.603 ; p=0.009\right.$ and $\chi^{2}(3)=12.064 ; p=0.007$ respectively), and, specifically, in both cases in the same two pairs of stages: between Assessment and Followup $(z=-2.461 ; p=0.014$ and $z=-2.527 ; p=$ 0.012 respectively) and between Treatment and Follow-up $(z=-2.776 ; p=0.006$ and $z=-3.062$; $p=0.002$ respectively).
Table 3

Descriptive statistics of components of instructional blocks by treatment stages

\begin{tabular}{ccccccccc}
\hline \multirow{2}{*}{ Instructional block } & \multicolumn{2}{c}{ Assessment } & \multicolumn{2}{c}{ Explanation } & \multicolumn{2}{c}{ Treatment } & \multicolumn{2}{c}{ Follow-up } \\
\cline { 2 - 9 } & $M$ & $S D$ & $M$ & $S D$ & $M$ & $S D$ & $M$ & $S D$ \\
\hline Formal & 58.68 & 37.81 & 67.85 & 34.99 & 77.57 & 8.4 & 35.26 & 28.11 \\
With specific situation & 28.36 & 23.07 & 40.92 & 34.6 & 31.1 & 11.91 & 34.15 & 27.98 \\
With example & 24 & 22.93 & 11.78 & 20.39 & 14.57 & 10.92 & 7.63 & 10.66 \\
With written & 43.31 & 34.5 & 25.78 & 39.75 & 28.94 & 21.03 & 9.31 & 28.16 \\
instruction & 16 & 26.63 & 4.42 & 9.98 & 5.52 & 8.36 & 0 & 0 \\
With role-playing & 16 & & & & & & &
\end{tabular}

We obtained the descriptive statistics shown in Table 4 in the analysis of the categories within the instructional blocks. In general, the data shows an increase of all types of discriminative in the explanation stages and a decrease in the follow-up stage, except for comprehension discriminative, which has a different trend: a higher rate of emission in the first stage of the intervention, and a progressive decrease as the intervention proceeds. Beyond these descriptive results, we only found statistically significant differences between stages for comprehension discriminative and performance discriminative $\left(\chi^{2}(3)=8.643 ; p=0.034\right.$ and $\chi^{2}(3)=12.000$; $p=0.007$, respectively). However, when we carried out a pairwise comparison analysis, we only found statistically significant differences between the Assessment and Treatment stages $(z=-2.521 ; p=0.012)$, and between the Treatment and Follow-up stages $(z=-2.521 ; p=$ 0.012 ) for performance discriminative.

\section{Table 4}

Descriptive statistics of categories within the instructional block by treatment stages

\begin{tabular}{ccccccccc}
\hline \multirow{2}{*}{ Discriminative } & \multicolumn{2}{c}{ Assessment } & \multicolumn{2}{c}{ Explanation } & \multicolumn{2}{c}{ Treatment } & \multicolumn{2}{c}{ Follow-up } \\
\cline { 2 - 9 } & $M$ & $S D$ & $M$ & $S D$ & $M$ & $S D$ & $M$ & $S D$ \\
\hline Opinion & 3.91 & 10.31 & 8.94 & 19.66 & 2.06 & 2.52 & 0.88 & 2.65 \\
Difficulty & 0 & 0 & 1.63 & 4.05 & 0.47 & 0.92 & 0 & 0 \\
Viability & 3.25 & 9.27 & 12.14 & 28.87 & 2.32 & 3.56 & 0 & 0 \\
Comprehension & 6.84 & 23.1 & 4.43 & 10.04 & 3.79 & 7.62 & 2.29 & 5.47 \\
Performance & 0 & 0 & 3.1 & 9.1 & 0.99 & 1.47 & 0 & 0 \\
\hline
\end{tabular}

b) Differences between treatment stages in the way of assessing homework compliance (review blocks):

Table 5 shows descriptive statistics for all the categories of interest within the review blocks. As is shown, specific compliance discriminative shows a small decrease in emission rate from the Assessment stage to the Explanation stage, but a progressive increase as the therapeutic process proceeds. Conversely, non-specific compliance 
discriminative shows a small increase in the Explanation stage but a progressive decrease at the end of the intervention. In both cases, differences between intervention stages are not statistically significant $\left(\chi^{2}(3)=0.78 ; p=0.854\right.$ and $\chi^{2}(3)=7.649 ; p=0.054$, respectively).

Regarding the other two types of compliance discriminative, we found a pronounced increase of emission of compliance discriminative of difficulty in the Explanation stage, but an important decrease in the Treatment stage that remains stable in the last intervention stage. The compliance discriminative of performance differed, remaining stable in the first two stages of the intervention, but the rate of emission increases in the Treatment stage and remains more or less stable, despite a small decrease, until the end of the intervention. Differences between intervention stages in these two categories were statistically significant $\left(\chi^{2}(3)\right.$ $=7.883 ; p=0.048$ and $\chi^{2}(3)=20.25 ; p$ $<0.01$, respectively). Specifically, statistically significant differences by pairs were found between Assessment and Treatment stages in both compliance discriminatives $(z=-2.430 ; p=$ 0.015 and $z=-3.464 ; p=0.001$ respectively) and also between Explanation and Treatment stages for the second of these $(z=-3.110 ; p=0.002)$.

Finally, the descriptive data of reinforcement category emission shows a small decrease from the beginning of the intervention to the Explanation stage, but a significant increase in Treatment, which remains more or less stable until the Follow-up, although there is a small decrease. These differences between stages had statistically significant results $\left(\chi^{2}(3)=7.927\right.$; $p=0.048)$ but only focused on the pairwise comparison Assessment and Explanation $(z=$ -2.032; $p=0.042$ ).

\section{Table 5}

Descriptive statistics of categories inside the review block by treatment stages

\begin{tabular}{ccccccccc}
\hline Categories & \multicolumn{1}{c}{ Assessment } & \multicolumn{2}{c}{ Explanation } & \multicolumn{2}{c}{ Treatment } & \multicolumn{2}{c}{ Follow-up } \\
\cline { 2 - 9 } & $M$ & $S D$ & $M$ & $S D$ & $M$ & $S D$ & $M$ & $S D$ \\
\hline $\begin{array}{c}\text { Specific compliance } \\
\text { discriminative }\end{array}$ & 52.21 & 42.29 & 45.71 & 49.87 & 60.31 & 18.88 & 62.63 & 28.34 \\
$\begin{array}{c}\text { Non-specific compliance } \\
\text { discriminative }\end{array}$ & 11 & 18.86 & 14.5 & 29.14 & 10.36 & 7.07 & 5.89 & 12.69 \\
$\begin{array}{c}\text { Compliance discriminative } \\
\text { of difficulty }\end{array}$ & 1.91 & 5.80 & 28.57 & 61.12 & 9.21 & 9.25 & 10.52 & 34.45 \\
$\begin{array}{c}\text { Compliance discriminative } \\
\text { of performance }\end{array}$ & 1.05 & 4.58 & 1.43 & 5.34 & 15.26 & 15.74 & 13.07 & 27.3 \\
Reinforcement & 41.68 & 37.98 & 20.89 & 38.69 & 53.94 & 27.17 & 48.05 & 41.03 \\
\hline
\end{tabular}

\section{Discussion}

The purpose of the present study was to analyze how behaviorist therapists give instructions for homework, assess the client's compliance, and consider the main results of the experimental field in instructions research. Although we can conclude that the proposed objective has been met, we can only partially confirm the first hypothesis, as explained below.

In the first place, we found that the emission of formal instructional blocks, which are considered the most accurate way of instructing, is the most frequent instructional block during much of the therapeutic process. This result is similar to findings by other researchers in the experimental and applied fields. On the one hand, some researchers from the experimental field note the importance of accuracy by specifying the behavior required to adjust the participants' performance to the experimental task and also to put their behavior into contact with the programmed contingencies (Hayes et al., 1986; Kaufman et al., 1966; Lippman \& Meyer, 1967; Miller et al., 2014; Weiner, 1970). On the other hand, researchers from the clinical field suggest the importance of being directive and specific about the behavior that the client must put into practice in order to encourage compliance and, ultimately, to experience natural contingencies (Cronin et al., 2015; Mazzullo, Lasagna, \& Griner, 1974; Morrison \& Wixted, 1989).

However, as shown, instructional blocks become informal in the last intervention stage; in other words, the therapist becomes less accurate when specifying the behavior to put into practice when giving instructions for homework. In a clinical sense, this result may be expected, given that the therapist no longer needs to be so directive and specific regarding the homework assignment after the Explanation and Treatment stages, perhaps because the client has probably acquired the new behavior and, therefore, the therapist only needs to suggest, even in a casual way, what the client must put into practice. Moreover, this interpretation could be related to the instructional blocks with written instructions and role-playing, displaying decreased emission 
frequency until the end of the therapeutic process. Similarly, from the perspective of clinical practice, it is reasonable to consider that, in the initial stages of the intervention, the client requires a demonstration through roleplaying of the new behavior instructed, and also tangible support for verbal instructions in the form of written instructions, in order to encourage the client to remember the task and implement it correctly (Cox, Tisdelle, \& Culbert, 1988; DiMatteo \& DiNicola, 1982; Huppert et al., 2006; Thompkins, 2002). However, these resources may not be necessary at this advanced stage of the intervention because the client may have automated the behavior.

From our perspective, the decrease in the previous three instructional blocks could be understood as a decrease in the concreteness of behavior or, in other words, a less accurate way of giving instructions. These findings can also be explained through experimental analysis of behavior, as some experiments revealed that, while the accuracy of the instructions issued is essential at the beginning of the learning process for acquiring the response and to putting it into contact with the contingencies, the application of contingencies is more important for maintaining the response (Ayllon \& Azrin, 1964; Baron \& Galizio, 1983; Cerutti, 1994; Cronin et al., 2015; Galizio, 1979; Hayes et al., 1986; Hojo, 2002; Kaufman et al., 1966; Martínez \& Ribes, 1996; Martínez et al., 2007; Martínez \& Tamayo, 2005; Mazzullo et al., 1974; Morrison \& Wizted, 1989; Okouchi, 1999; Ortiz et al., 2007; 2008; Podlesnik \& Chase, 2006; Radley et al., 2018).

This interpretation suggests that, in the early stages of intervention, the therapist should be specific when instructing tasks (for example, 'this week you have to expose yourself to touch the subway bars at least once a day, as we will practice now in session'). The therapist should also ensure accuracy by providing written tasks and carrying out controlled exposures to the behavior within the session such as role-playing. These accurate instructions may play a role in controlling the client's behavior in the early stages of intervention. However, towards the end of the intervention, this behavior control may be due to the effect of contingencies, when the client has learned the behavior and experienced natural contingencies (for example, checking that anxiety diminishes despite having touched the subway bar). Thus, given that the accuracy of instructions seems less important in the final stage of intervention, the therapist can use general instructions (for example, 'remember, the exposure tasks').

Unlike the previous findings, which allow us to confirm the first hypothesis, the stability in the emission rates of instructional blocks with specific situations and examples is the opposite of what we expected. Another striking result is the low rate of emission of these instructional blocks, which do not exceed 41 percent and 24 percent, respectively, in any intervention stage. These results may be due to the therapist seeking to help the client perform the new behavior in different environments, rather than merely in the specified situation or example. This interpretation is strengthened by some experimental studies, which suggest that following instructions in a specific situation may provoke a context-specific response, and therefore hinder sensitivity to other environments (Braem et al., 2017).

To complete our evaluation of the first hypothesis, we refer to the results of the categories within the instructional block, and specifically to the emission rate of discriminative types throughout the therapeutic process, which disagree with what we expected. Statistical differences between intervention stages were found only for the performance discriminative. A possible explanation for these results is that pronounced differences in variability of emission of these categories between stages make it difficult to estimate statistical significance. However, performance discriminative shows a different trend, a fact that has repercussions in the statistical significance found in the differences between intervention stages. In this sense, the findings suggest that therapists are more interested in assessing how the client will put the instructed task into practice in the Treatment stage. This result is congruent with the clinical perspective, because therapists most 
frequently assign therapeutic tasks in this stage, and, in most cases, require the implementation of new behaviors. Thus, a therapist may be interested in anticipating potential difficulties in task implementation to adjust it to contingencies (e.g., 'tell me how you are going to tell her'). However, this is not essential in the final stage of the intervention, when the client has probably acquired the behavior correctly and, hence, the emission rate of this discriminative decreases. Moreover, this result is in accordance with clinical guidelines that note the importance of a collaborative attitude from the therapist through the use of questions when assigning homework (e.g., discriminative) to anticipate possible obstacles for compliance (Cronin et al., 2015; Freeman \& Rosenfield, 2002; Kazantzis et al., 2017; Kazantzis \& Deane, 1999; Kazantzis \& Lampropoulos, 2002; Okamoto et al., 2019).

Regarding the second hypothesis on the review blocks, the emission rate of specific and non-specific compliance discriminative remains stable throughout all intervention stages. These findings suggest that the therapist assesses compliance in the same way throughout the intervention, and consequently,rejects our hypothesis. Additionally, we found a higher emission rate of specific, as opposed to nonspecific, compliance, which suggests that the therapist asks about compliance about specific tasks (e.g., 'have you touched the subway bars daily'?) and not for general compliance (e.g., 'have you done your homework'?). We find two plausible explanations for these findings: on the one hand, therapists may want to maintain the behavior changes achieved by the client and therefore continue the compliance assessment of each specific task. Furthermore, this interpretation could be related to the recommendation from applied researchers to therapists, which advocates being directive when assessing homework compliance (e.g., Garland $\&$ Scott, 2002). On the other hand, the fact that the client has to report on their compliance may indicate that the therapist hopes to ensure that the client establishes a relationship between their response to contingencies, including the antecedents and consequences, which has been shown in experimental research to have a positive effect on future performance (Ortiz et al., 2006; Ortiz, 2010).

The results of the compliance discriminatives for difficulty and performance were also different from expected: an increase in the emission rate in the Treatment stage, and stability from this stage onwards to the end of the intervention. Specifically, the only statistically significant differences found were between Assessment and Treatment for both compliance discriminatives, and between Explanation and Treatment for the second. These findings lead us to reject the proposed hypothesis again, and to raise a possible explanation similar to the previously analyzed compliance discriminatives. Additionally, therapists continuing to assess compliance with tasks until the final stage of the intervention, probably to ensure behavioral changes, may also be interested in hearing the client's feedback regarding potential difficulties in the performance of the instructed tasks to ensure their correct implementation.

In addition to this, it is logical that there should be an increase of these compliance discriminatives from the Treatment stage, given that this was the stage of the therapeutic process when therapists began to give instructions for more complex tasks, often requiring difficult changes in behavioral habits. Thus, therapists want to know not simply whether clients are complying with tasks, but also how they are complying, a therapeutic strategy frequently recommended to clinicians (Garland \& Scott, 2002).

Finally, the results on the reinforcement emission rate, which demonstrate that the rate is maintained until the last stage of the intervention, also lead us to reject the hypothesis formulated. From the perspective of clinical practice, this result could be interpreted as the therapist's desire to maintain behavioral changes by managing contingencies, until the natural contingencies are effective. For example, a therapist could reinforce the client when reports the compliance with the task 'going out with friends on Saturday night' throughout the therapy to ensure the 
task compliance until the natural contingency (having a good time on Saturday night) occurs. Moreover, this assumption is strengthened by experimental studies that demonstrate the role of reinforcement for maintaining responses learned through instructions (Baron \& Galizio, 1983; Cerutti, 1994; Galizio, 1979; Hojo, 2002; Martínez \& Ribes, 1996; Martínez et al., 2007; Martínez \& Tamayo, 2005; Okouchi, 1999; Olaff \& Holth, 2020; Ortiz et al., 2007; Ortiz et al., 2008; Podlesnik \& Chase, 2006). Nonetheless, the reinforcement rate emission is not maintained throughout every stage, decreasing the Explanation stage. The therapeutic process structure may explain this finding, because the therapist explains the functional analysis to the client during this stage and, therefore, it is probable that the therapist is focusing on explaining the client's problem rather than assessing compliance with tasks.

The present study has provided a descriptive longitudinal view of how therapists instruct and review the task compliance throughout the psychological intervention. In general, findings demonstrate that clients are instructed less accurately as the intervention progresses; nevertheless, the way that compliance is reviewed is maintained. Illustratively, this process displays parallels with laboratory experiments in which, after instructing the participants, the instructions are withdrawn in order to observe the learning responses when the participants come into contact with the programmed contingencies. However, counters are maintained throughout all stages to record these responses and provide contingencies. From our perspective, in psychological treatments, changes in the therapist's verbal behavior when giving instructions and assessing compliance could also be the result of a similar learning process. However, to prove this hypothesis, it would be necessary to incorporate the client's verbal behavior to analyze therapistclient interaction. This represents a limitation of the present study, but a prospective line of investigation for future research.

Other limitations to this study should be acknowledged: analysis of the therapist's verbal behavior by successive stages instead of session by session; analysis of all the tasks instructed rather than separating them by type, and the use of experimental findings to support our results. Despite these limitations, we consider that the present study represents an interesting and novel attempt to advance the scientific study of behavior within the clinical context, supported by consolidated lines of research in experimental analysis behavior. Although we are conscious of the limitations of comparing laboratory experiments with those that take place in a clinical context, we also aware of the need in applied psychology to incorporate research findings in controlled contexts for a better understanding of human behavior and, ultimately, to establish a link between theory and practice in psychology.

\section{References}

Ayllon, T., \& Azrin, N. H. (1964). Reinforcement and instructions with mental patients. Journal of the Experimental Analysis of Behavior, 7(4), 327-331. https://doi.org/10. 1901/jeab.1964.7-327

Bakeman, R. (2000). Behavioural observation and coding. In $\mathrm{H}$. T. Reis \& C. M. Judd (Eds.), Handbook of Research methods in social and personality psychology (pp. 138-159). Cambridge: Cambridge University Press.

Baron, A., \& Galizio, M. (1983). Instructional Control of Human Operant Behaviour. The Psychological Record, 33(4), 495-520.

Braem, S., Liefooghe, B., De Houwer, J., Brass, M., Abrahamse, E. L., \& Braem, S. (2017). There are limits to the effects of task instructions: Making the automatic effects of task instructions context-specific takes practice. Journal of Experimental Psychology. Learning, Memory, and Cognition, 43(3), 394-403. https://doi.org/10.1037/xlm00003 10

Cerutti, D. T. (1994). Compliance with instructions: Effects of randomness in scheduling and monitoring. The 
Psychological Record, 44, 259-269. https://do i.org/10.1007/bf03395133

Conklin, L. R., Strunk, D. R., \& Cooper, A. A. (2018). Therapist behaviours as predictors of immediate homework engagement in cognitive therapy for depression. Cognitive Therapy and Research, 42 (1), 16-23. https:// doi.org/10.1007/s10608-017-9873-6

Coon, D. W., \& Gallagher-Thompson, D. (2002). Encouraging homework completion among older adults in therapy. Journal of Clinical Psychology, 58(5), 549-563. https://doi.org/ 10.1002/jclp.10032

Cox, D. J., Tisdelle, D. A., \& Culbert, J. P. (1988). Increasing adherence to behavioral homework assignments. Journal of behavioral medicine, 11(5), 519-522.

Cronin, T. J., Lawrence, K. A., Taylor, K., Norton, P. J., \& Kazantzis, N. (2015). Integrating between-session interventions (Homework) in therapy: The importance of the therapeutic relationship and cognitive case conceptualization. Journal of Clinical Psychology, 71(5), 439-450. https://doi.org/ $10.1002 /$ jclp. 22180

Dattilio, F. M. (2002). Homework assignments in couple and family therapy. Journal of Clinical Psychology, 58(5), 535-547. https://doi.org/ 10.1002/jclp.10031

DiMatteo, M. R., \& DiNicola. D. D. (1982). Achieving patient compliance: The psychology of the medical practitioner's role. New York: Pergamon.

Follette, W. C., Naugle, A. E., \& Callaghan, G. M. (1996). A radical behavioural understanding of the therapeutic relationship in effecting change. Behavior Therapy, 27, 623-641. https://doi.org/10.10 16/s0005-7894(96)80047-5

Freeman, A., \& Rosenfield, B. (2002). Modifying therapeutic homework for patients with personality disorders. Journal of Clinical Psychology, 58(5), 513-524. https://doi.org/ 10.1002/jclp.10029

Froján, M. X., Montaño, M., \& Calero, A. (2010). therapists' verbal behaviour analysis: A descriptive approach to the psychotherapeutic phenomenon. The
Spanish Journal of Psychology, 13(02), 914-926. https://doi.org/10.1017/s1138741 600002560

Froján M. X., \& Ruiz, E. M. (2013). Análisis funcional de la interacción terapéutica. Conductual, 1(1), 72-92. http://conductual.com/articulos/An alisis\%20funcional\%20de\%20la\%20intera ccion\%20terapeutica.pdf

Galizio, M. (1979). Contingency-shaped and rule governed behaviour: instructional control of human loss avoidance. Journal of the Experimental Analysis of Behavior, 31, 53-70. https://doi.org/10.1901/jeab.1979.31-53

Garland, A., \& Scott, J. (2002). Using homework in therapy for depression. Journal of Clinical Psychology, 58(5), 489-498. https://doi.org/ 10.1002/jclp.10027.

Hayes, S. C., Brownstein, A. J., Haas, J. R., \& Greenway, D. E. (1986). Instructions, multiple schedules, and extinction: distinguishing rule-governed from schedule-controlled behaviour. Journal of the Experimental Analysis of Behavior, 46(2), 137-147. https://doi.org/10 $.1901 /$ jeab.1986.46-137

Hojo, R. (2002). Effects of instructional accuracy on a discrimination task. The Psychological Record, 52, 493-507. https://doi.org/10.100 $7 / \mathrm{bf03395200}$

Huppert, J. D., Roth L. D., \& Foa, E. B. (2006). The Use of homework in behaviour therapy for anxiety disorders. Journal of Psychotherapy Integration, 16(2), 128-139. h ttps://doi.org/10.1037/1053-0479.16.2.128

Kaufman, A., Baron, A., \& Kopp, R. E. (1966). Some effects of instructions on human operant behavior. Psychonomic Monograph Supplements, 7(11), 243-250.

Kazantzis, N., Brownfield, N. R., Mosely, L., Usatoff, A. S., \& Flighty, A. J. (2017). Homework in cognitive behavioral therapy. Psychiatric Clinics of North America, 40(4), 625-639. https://doi.org/10.1016/j.psc.2017 .08 .001

Kazantzis, N., \& Deane, F. P. (1999). Psychologists' use of homework assignments in clinical practice. Professional Psychology: 
Research and Practice, 30(6), 581-585. https ://doi.org/10.1037/0735-7028.30.6.581

Kazantzis, N., \& Lampropoulos, G. K. (2002). Reflecting on homework in psychotherapy: what can we conclude from research and experience? Journal of Clinical Psychology, 58(5), 577-585. https://doi.org/10.1002/jcl p. 10034

Kazantzis, N., Whittington, C., Zelencich, L., Kyrios, M., Norton, P. J., \& Hofmann, S. G. (2016). Quantity and quality of homework compliance: A meta-analysis of relations with outcome in cognitive behavior therapy. Behavior Therapy, 47, 755-772. https://doi.org/10.1016/j.beth.201 6.05 .002

Kissi, A., Hughes, S., De Schryver, M., De Houwer, J., \& Crombez, G. (2018). Examining the moderating impact of plys and tracks on the insensitivity effect: A preliminary investigation. The Psychological Record, 68(4), 431-440. https://doi.org/10.1 007/s40732-018-0286-z

Landis, J. R., \& Koch, G. G. (1977). The measurement of observer agreement for categorical data. Biometrics, 33, 159-174. h ttps://doi.org/10.2307/2529310

Lippman, L. G., \& Meyer, M. E. (1967). Fixed interval performance as related to instructions and to subjects' verbalizations of the contingency. Psychonomic Science, 8(4), 135-136. https://doi.org/10.3758/bf03 331586

Martínez, H., Ortiz, G., \& González, A. (2007). Efectos diferenciales de instrucciones y consecuencias en ejecuciones de discriminación condicional humana. Psicothema, 19(1), 14-22. http://www.psicot hema.com/psicothema.asp? $\mathrm{id}=3322$

Martínez, H., \& Ribes, E. (1996). Interactions of contingencies and instructional history on conditional discrimination. The Psychological Record, 46, 301-318.

Martínez, H., \& Tamayo, R. (2005). Interactions of contingencies, instructional accuracy, and instructional history in conditional discrimination. The Psychological Record,
5(4), 633-646. https://doi.org/10.1007/bf03 395531

Mazzullo, J. M., Lasagna, L., \& Griner, P. F. (1974). Variations in interpretation of prescription instructions: The need for improved prescribing habits. Jama, 227(8), 929-931. https://doi.org/10.1001/jama.227. 8.929

Miller, J. R., Hirst, J. M., Kaplan, B. A., Reed, F. D. D., \& Reed, D. D. (2014). Effects of mands on instructional control: A laboratory simulation. The Analysis of Verbal Behaviour, 30(2), 100-112. https://doi.org/1 0.1007/s40616-014-0015-x

Montaño, M., Martínez, H., Froján, M. X., \& Calero, A. (2013). The role of verbal behavior in the analysis of the therapeutic process. Conductual, International Journal of Interbehaviorism and Behavior Analysis, 1(2). http://www.itemadrid.net/pdf/the-rol e-of-verbal-behavior-in-the-analysis-of-the -therapeutic-process.pdf

Morrison, R. L., \& Wixted, J. L. (1989). Social Skills Training. In A. S. Bellack (Ed.), A Clinical Guide for the Treatment of Schizophrenia (pp. 237-261). NY: Plenum Press.

Okamoto, A., Dattilio, F. M., Dobson, K. S., \& Kazantzis, N. (2019). The therapeutic relationship in cognitivebehavioral therapy: Essential features and common challenges. Practice Innovations, 4(2), 112-123. https://doi.org/10.1037/pri0 000088

Okouchi, H. (1999). Instructions as discriminative stimuli. Journal of the Experimental Analysis of Behavior, 72(2), 205-214. https://doi.org/10.1901/jeab.1999 $.72-205$

Olaff, H. S., \& Holth, P. (2020). The emergence of bidirectional naming through sequential operant instruction following the establishment of conditioned social reinforcers. The Analysis of Verbal Behavior, 1-28. https://doi.org/10.1007/s40616-019-0 $0122-0$

Ortiz, G. (2010). Precisión de descripciones, retroalimentación y conocimiento de la 
finalidad de la descripción poscontacto sobre la ejecución, elaboración y transmisión de descripciones. Acta Comportamentalia, 18(2), 189-213.

Ortiz, G., de la Rosa, E., Padilla, R., Pulido, E., \& Velez, H. (2008) Efecto de la precisión e historia instruccional en la insensibilidad al cambio contingencial en tareas de igualación de la muestra de primer orden en humanos. Acta Comportamentalia, 16, 167-181.

Ortiz, G., González, A., Rosas, M., \& Alcaraz, F. (2006). Efectos de la precisión instruccional y la densidad de retroalimentación sobre el seguimiento instruccional, la elaboración y transmisión de descripciones en tareas de discriminación condicional. Acta Comportamentalia, 14, 103-130.

Ortiz, G., Pacheco, V., Bañuelos, I., \& Plascencia, L. (2007). Efecto del contacto con instrucciones, la especificidad e historia instruccional en la insensibilidad al cambio contingencial en tareas de igualación de la muestra de primer orden en humanos. Acta Colombiana de Psicología, 10(2), 107-115.

Podlesnik, C. A., \& Chase, P. N. (2006). Sensitivity and Strength: Effects of Instructions on Resistance to Change. The Psychological Record, 56(2), 303-320. https: //doi.org/10.1007/bf03395552

Radley, K. C., Dart, E. H., Helbig, K. A., \& Schrieber, S. R. (2018). An additive analysis of lag schedules of reinforcement and rules on novel responses of individuals with autism spectrum disorder. Journal of Developmental and Physical Disabilities, 1-14. https://doi.org/10.1007/s10882-018-9 606-0

Rosenfarb, I. S. (1992). A Behaviour Analytic Interpretation of the Therapeutic Relationship. Psychological Record, 42, 341-354. https://doi.org/10.1007/bf033996 06

Ruiz, E., Froján, M. X., \& Calero, A. (2013). Análisis de la conducta verbal del cliente durante el proceso terapéutico. Anales de Psicología, 29(3), 779-790. https://doi.org/1 0.6018/analesps.29.3.135401
Ruiz, E., Froján, M. X., \& Galván, N. (2015). Verbal interaction patterns in the clinical context: A model of how people change in therapy. Psicothema, 27(2), 99-107. https:// doi.org/10.7334/psicothema2014.119

Shelton, J. L., \& Levy, R. L. (1981). A survey of the reported use of assigned homework activities in contemporary behavior therapy literature. The Behavior Therapist, 4, 13-14. https://psycnet.apa.org/record/1982 $-21726-001$

Thompkins, M. A. (2002). Guidelines for enhancing homework compliance. Journal of clinical psychology, 58(5), 565-576. https: //doi.org/10.1002/jclp.10033

Tsai, M., Kohlenberg, R. J., Kanter, J. W. Kohlenberg, B., Follette, W. C., \& Callaghan, G.M. (2009). A Guide to functional analytic psychotherapy. Awareness, courage, love and behaviorism. NY: Springer.

Vargas, I., Pardo, R., Martínez, H., \& Froján, M. X. (2017). The therapist's rulelike verbalizations throughout the clinical process. Universitas Psychologica, 16(1), 25-39. https://doi.org/10.11144/Javeriana.u psy16-1.vtrt

Weiner, H. (1970). Instructional control of human operant responding during extinction following fixed-ratio conditioning. Journal of the Experimental Analysis of Behavior, 13, 391-394. https://do i.org/10.1901/jeab.1970.13-391

\section{Notes}

* Research article. 